\title{
Nucleus Accumbens Core Mammalian Target of Rapamycin Signaling Pathway Is Critical for Cue-Induced Reinstatement of Cocaine Seeking in Rats
}

\author{
Xi Wang, Yi-xiao Luo, Ying-ying He, Fang-qiong Li, Hai-shui Shi, Li-fen Xue, Yan-xue Xue, and Lin Lu \\ National Institute on Drug Dependence, Peking University, Beijing 100191, China
}

Relapse to drug seeking was studied using a rodent model of reinstatement induced by exposure to drug-related cues. The mammalian target of rapamycin (mTOR), a serine/threonine protein kinase that regulates cell growth and survival by controlling translation in response to nutrients and growth factors, has been demonstrated to be involved in neuronal adaptations that underlie drug addiction and learning and memory. We investigated the potential role of the mTOR signaling pathway in relapse to cocaine seeking by using the cue-induced reinstatement model in self-administering rats. We found that exposure to a cocaine-related cue induced reinstatement to cocaine seeking and increased phosphorylation of p70s6 kinase (p70s6k) and ribosomal protein s6 (rps6), measures of mT0R activity, in the nucleus accumbens (NAc) core but not shell. Furthermore, inhibition of NAc core but not shell p70s6k and rps6 phosphorylation by rapamycin decreased cue-induced reinstatement of cocaine seeking. Finally, stimulation of NAc core p70s6k and rps6 phosphorylation by NMDA enhanced cue-induced reinstatement, an effect reversed by rapamycin pretreatment. Additionally, rapamycin infusion into the NAc core or shell did not alter ongoing cocaine self-administration or cue-induced reinstatement of sucrose seeking. These findings indicate that cue-induced reinstatement of cocaine seeking is mediated by activation of the mTOR signaling pathway in the NAc core.

\section{Introduction}

Relapse to cocaine use can occur after prolonged periods of abstinence (Gawin and Kleber, 1986; O’Brien, 1997). This relapse is often caused by craving-provoking environmental cues that were paired previously with the rewarding effects of cocaine (O'Brien et al., 1998; Childress et al., 1999). Cue-induced relapse to drug seeking has been assessed in a reinstatement model, a commonly used preclinical model of drug craving and relapse (See, 2002; Shaham et al., 2003; Epstein et al., 2006). In cue-induced reinstatement studies, rats are first trained to self-administer a drug or nondrug reward; each reward delivery is temporally paired with a discrete cue (e.g., tone, light). Lever pressing is then extinguished in the absence of the discrete cue. During reinstatement testing, exposure to the discrete cue, which is earned contingently by responding on the drug-associated lever, reinstates drugseeking behavior (Meil and See, 1997; Kruzich and See, 2001).

The mammalian target of rapamycin (mTOR), a serine/threonine protein kinase, regulates cell growth and survival by controlling translation in response to nutrients and growth factors

Received March 11, 2010; revised July 31, 2010; accepted Aug. 4, 2010.

This work was supported in part by National Basic Research Program of China Grant 2009CB522004, Natural Science Foundation of China Grant 30725016, and Natural Science Foundation of Beijing Municipality Grant 09G0762. We thank Dr. Haifeng Zhai for the technical assistance and Dr. Yavin Shaham for his helpful comments on this manuscript.

The authors declare that they do not have any conflicts of interest related to the data presented in this manuscript.

Correspondence should be addressed to Dr. Lin Lu, National Institute on Drug Dependence, Peking University, 38 , Xue Yuan Road, Beijing 100191, China. E-mail: linlu@bjmu.edu.cn.

DOI:10.1523/JNEUROSCI.1264-10.2010

Copyright $\odot 2010$ the authors $\quad$ 0270-6474/10/3012632-10\$15.00/0
(Gingras et al., 2001; Proud, 2007). mTOR activation can be specifically inhibited by rapamycin (Sabatini et al., 1997) and leads to the phosphorylation of the 40S ribosomal protein S6 (rps6) via phosphorylation and activation of p70S6 kinase (p70s6k) (Proud, 2007). Phosphorylation of rps6 changes the interaction of the protein with these components, thereby promoting mRNA translation (Tang et al., 2001).

mTOR signaling also plays a role in learning and memory. Long-term potentiation (LTP) (a cellular correlate of learning and memory) in Aplysia cultured neurons is blocked by inactivation of mTOR with rapamycin incubation (Casadio et al., 1999; Steward and Schuman, 2003). Additionally, LTP induced by brain-derived neurotrophic factor in the hippocampus is blocked by rapamycin, which specifically inhibits the mTOR signaling pathway (Tang et al., 2002; Takei et al., 2004). Spatial memory formation and the memory-enhancing effect of glucose is dependent on mTOR signaling in the dorsal hippocampus (Dash et al., 2006). Finally, injection of the mTOR inhibitor rapamycin into the amygdala blocks the consolidation and reconsolidation of fear memory (Parsons et al., 2006). These findings suggest that mTOR plays a critical role in the neural synaptic plasticity that underlies learning and memory. Based on these previous studies, we assessed the role of the mTOR signaling pathway in the nucleus accumbens (NAc) in cue-induced reinstatement of cocaine seeking. We chose the NAc because of its critical role in cueinduced drug seeking (Bossert et al., 2005; See, 2005).

\section{Materials and Methods}

\section{Subjects}

Male Sprague Dawley rats (weighing 240-260 g on arrival) were housed in groups of five under controlled temperature $\left(23 \pm 2^{\circ} \mathrm{C}\right)$ and humidity 


\section{A NAc core}
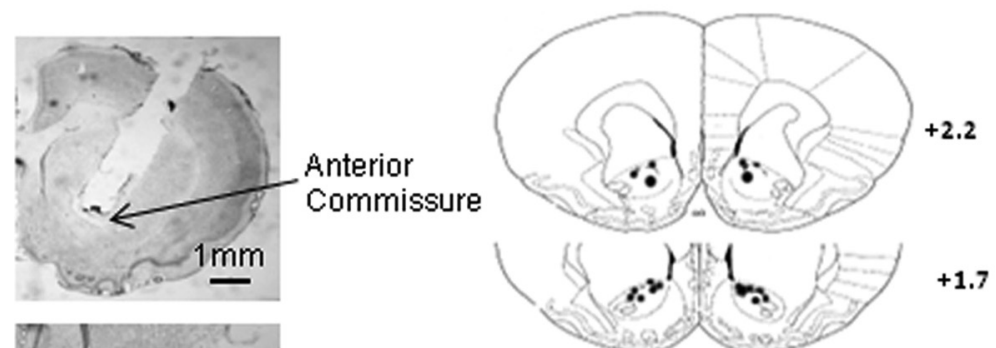

Y
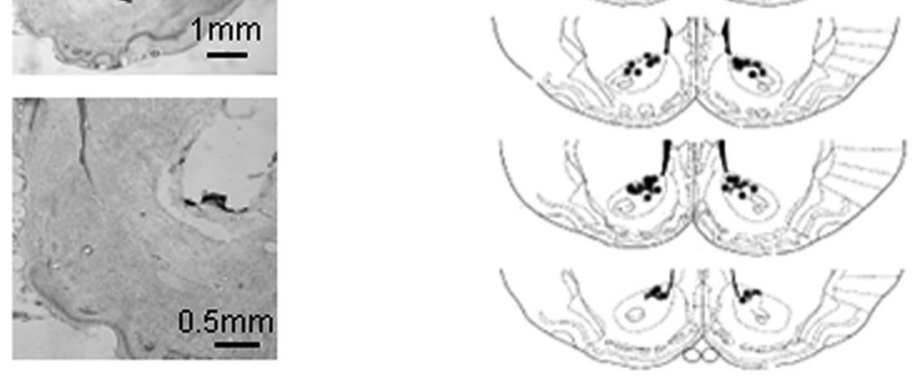

\section{B NAc shell}
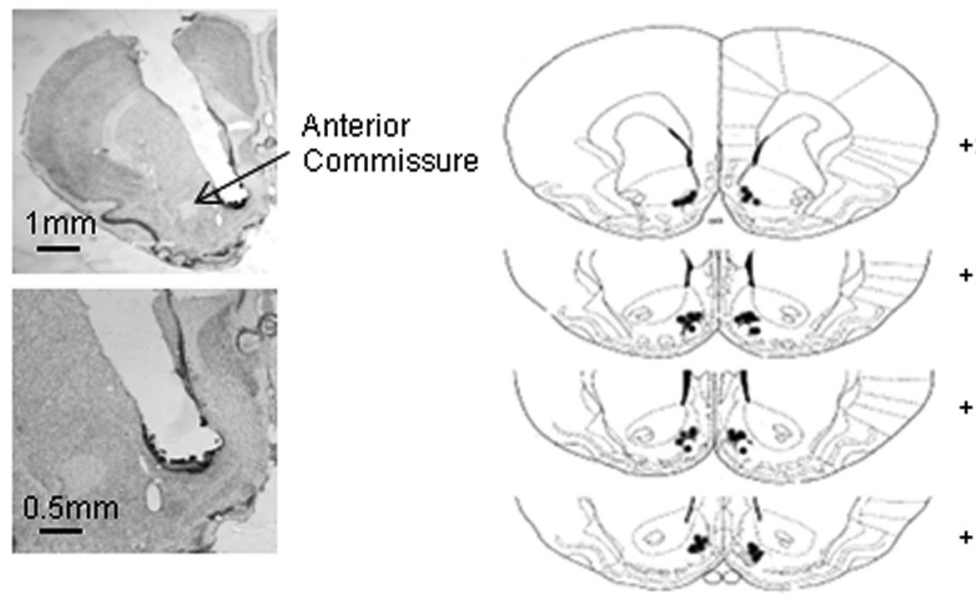

Figure 1. Representative cannula placements in the NAc core and shell of naive rats injected with 20\% DMSO.

$(50 \pm 5 \%)$ and maintained on a $12 \mathrm{~h}$ light/dark cycle with access to food and water ad libitum. All animal procedures were performed in accordance with the National Institutes of Health Guide for the Care and Use of Laboratory Animals, and the experiments were approved by the Local Animal Use Committee.

\section{Intracranial and intravenous surgery}

Rats (weighing 300-320 g during surgery) were anesthetized with sodium pentobarbital anesthesia $(60 \mathrm{mg} / \mathrm{kg}$, i.p.). Catheters were inserted into the right jugular vein with the tip terminating at the opening of the right atrium as described previously (Shaham et al., 1997; Lu et al., 2004). Guide cannulae ( 23 gauge; Plastics One) were implanted bilaterally $1 \mathrm{~mm}$ above the NAc core or shell. The cannulae were placed at a $16^{\circ}$ angle toward the midline to avoid penetration of the lateral ventricle. The following NAc core coordinates were used: anteroposterior, $+1.5 \mathrm{~mm}$; lateral, $\pm 3.8 \mathrm{~mm}$; dorsoventral, $-6.2 \mathrm{~mm}$. The following NAc shell coordinates were used: anteroposterior, $+1.8 \mathrm{~mm}$; lateral, $\pm 3.2 \mathrm{~mm}$; dorsoventral, $-6.6 \mathrm{~mm}$ (Zangen et al., 2006; Bossert et al., 2007; Xu et al., 2009). The cannulae were anchored to the skull with stainless steel screws and dental cement. A stainless steel stylet blocker was inserted into each cannula to maintain patency and prevent infection. All rats were allowed to recover for 5-7 d after surgery.

\section{Intracranial injections}

Rapamycin $(50 \mu \mathrm{g} / 0.5 \mu \mathrm{l})$ and NMDA (250 ng/0.5 $\mu \mathrm{l}$; RBI) were infused bilaterally into the NAc core or shell with Hamilton syringes connected
$+1.7$

$+1.6$

$+1.2$

$+2.2$

$+1.7$

$+1.6$

$+1.2$

to 30 gauge injectors (Plastics One). NMDA was dissolved in sterile saline, and the $\mathrm{pH}$ of the drug solution was adjusted to 7.4 by adding $\mathrm{NaOH}$. The mTOR inhibitor rapamycin (Xinmei Technology Corporation) was dissolved in 20\% dimethylsulfoxide (DMSO) (Lu et al., 2005). A total volume of $0.5 \mu \mathrm{l}$ was infused into each side over $1 \mathrm{~min}$, and the injector was kept in place for an additional $1 \mathrm{~min}$ to allow for diffusion. The doses of rapamycin and NMDA were based on previous reports (Lu et al., 2005; Parsons et al., 2006).

\section{Histology}

Histology slides were obtained from naive rats that were injected with $20 \%$ DMSO in the NAc core and shell. Naive rats were used because the NAc core and shell of the experimental groups were dissected for Western blot assays. After $20 \%$ DMSO injection, naive rats were anesthetized with sodium pentobarbital $(100 \mathrm{mg} / \mathrm{kg}$, i.p.) and transcardially perfused with paraformaldehyde. Cannula placements were assessed by Nissl staining with a $40 \mu \mathrm{m}$ thickness under light microscopy (Wang et al., 2008). The locations of representative cannula tips are shown in Figure 1.

\section{Tissue sample preparation}

After the end of the 30 min reinstatement test, the rats were decapitated. Brains were quickly extracted, frozen in $-60^{\circ} \mathrm{C} \mathrm{N}$-hexane, and transferred to $\mathrm{a}-80^{\circ} \mathrm{C}$ freezer. Using a freezing cryostat $\left(-20^{\circ} \mathrm{C}\right.$; Reichert-Jung 2800 Frigocut $\mathrm{E}$ ), bilateral tissue punches (12 or 16 gauge) of the NAc core or shell were taken from 1-mmthick coronal sections $\sim 2.52 \mathrm{~mm}$ from bregma (Lu et al., 2005; Li et al., 2008). Tissue punches were homogenized (three times for $10-15 \mathrm{~s}, 5 \mathrm{~s}$ interval) with an electrical disperser (Wiggenhauser) after $30 \mathrm{~min}$ with radioimmunoprecipitation assay (RIPA) lysis buffer (Beyotime Biotechnology) (20 mu Tris, pH 7.5, $150 \mathrm{~mm}$ $\mathrm{NaCl}, 1 \%$ Triton X-100, $2.5 \mathrm{~mm}$ sodium pyrophosphate, $1 \mathrm{~mm}$ EDTA, $1 \% \mathrm{Na}_{3} \mathrm{VO}_{4}, 0.5$ $\mu \mathrm{g} / \mathrm{ml}$ leupeptin, and $1 \mathrm{~mm}$ phenylmethanesulfonyl fluoride). The homogenate was then subjected to $10,000 \times g$ centrifugation for $10 \mathrm{~min}$ at $4^{\circ} \mathrm{C}$. All of the above procedures were performed under low temperature $\left(0-4^{\circ} \mathrm{C}\right)$. The protein concentrations of all samples were determined using the bicinchoninic acid assay (Beyotime Biotechnology). Samples were further diluted in RIPA lysis buffer to equalize the protein concentrations.

\section{Western blot assays}

The samples were treated according to previous studies (Lu et al., 2003, 2005 ) with some modifications. Four times loading buffer (16\% glycerol, $20 \%$ mercaptoethanol, $2 \%$ SDS, and $0.05 \%$ bromophenol blue) was added to each sample (3:1, sample/loading buffer) before boiling for 3 min. Samples were cooled and subjected to SDS-PAGE (10\% acrylamide/ $0.27 \% \mathrm{~N}, N^{\prime}$-methylenebisacryalamide resolving gel) for $\sim 30 \mathrm{~min}$ at 80 $\mathrm{V}$ in stacking gel and $\sim 1 \mathrm{~h}$ at $120 \mathrm{~V}$ in resolving gel. For each electrophoresis, increasing amounts of protein pooled from all samples were electrophoresed to produce a standard curve. Proteins were transferred electrophoretically to Immobilon-P transfer membranes (Millipore Corporation) at $0.25 \mathrm{~A}$ for $3 \mathrm{~h}$. Membranes were dipped in blocking buffer [5\% skimmed dry milk in Tris-buffered saline plus $0.05 \%$ Tween 20 (TBST), $\mathrm{pH}$ 7.4] for $1 \mathrm{~h}$ at room temperature on an orbital shaker and then were incubated overnight at $4^{\circ} \mathrm{C}$ with anti-phospho-p70s6k antibody (1:500; Cell Signaling Technology), anti-p70s6k antibody (1:500; Cell Signaling Technology), anti-phospho-rps6 antibody (1:500; Cell 
Signaling Technology), or anti-rps6 antibody (1:500; Cell Signaling Technology) in TBST plus 5\% bovine serum albumin and $0.05 \%$ sodium azide. The next day, after four 6-min washes in TBST buffer, blots were incubated for $45 \mathrm{~min}$ at room temperature on a shaker with horseradish peroxidase-conjugated secondary antibody (goat anti-rabbit IgG or goat anti-mice IgG; Santa Cruz PI-1000; Vector Laboratories) diluted 1:5000 in blocking buffer. After four 6-min washes in TBST, the blots were incubated with a layer of a Super Signal Enhanced Chemiluminescence substrate mixture (Detection Reagents 1 and 2, 1:1 ratio; Pierce Biotechnology) for $1 \mathrm{~min}$ at room temperature. Excess mixture was dripped off before blots were wrapped with a clean piece of plastic wrap (no bubbles between blot and wrap), and the blots were then exposed against x-ray film (Eastman Kodak) for 1-2 min. Band intensities were quantified using Quantity One software (version 4.0.3; Bio-Rad). Band intensities from each test sample were compared with the band intensities from the standard curves. The amount of the protein of interest in each sample was interpolated from the standard curve (Lu et al., 2003, 2005).

\section{Experimental procedures}

Intravenous cocaine self-administration training (experiments 1-5). The chambers (AniLab Software and Instruments) were equipped with two nose-poke operandi (ENV-114M; Med Associates) located $9 \mathrm{~cm}$ above the floor of the chambers. Nose pokes in one (active) operandum led to cocaine infusions that were accompanied by a $5 \mathrm{~s}$ tone-light cue. Nose pokes in the other (inactive) operandum were also recorded but had no consequence. The modified cannula on the rat's skull was connected to a liquid swivel (Instech) with polyethylene-50 tubing protected by a metal spring and connected to a $10 \mathrm{ml}$ syringe infusion pump. Rats were trained to self-administer cocaine $\mathrm{HCl}(0.75 \mathrm{mg} / \mathrm{kg}$ per infusion $)$ during three $1 \mathrm{~h}$ daily sessions separated by 5 min over $10 \mathrm{~d}$. The sessions began at the onset of the dark cycle. A fixed-ratio one reinforcement schedule was used, with a $40 \mathrm{~s}$ timeout period after each infusion. Each session began with the illumination of a house light that remained on for the entire session. To facilitate the acquisition of cocaine self-administration, food was removed from the chambers during the $3 \mathrm{~h}$ sessions on the first $5 \mathrm{~d}$. The number of cocaine infusions was limited to 20 per hour. At the end of the training phase, the groups in the different experimental conditions were matched for their cocaine intake during training. These training conditions were based on our previous studies (Lu et al., 2005, 2009).

Intravenous saline self-administration (experiment 1). The experimental conditions were identical to those described above for cocaine selfadministration, with the exception that active nose-poke responses led to infusions of saline ( $0.1 \mathrm{ml} /$ infusion).

Sucrose self-administration (experiment 6). The experimental conditions were identical to those described above for cocaine self-administration, with the exception that active nose-poke responses led to $0.1 \mathrm{ml}$ of sucrose (10\%) delivered into a liquid receptacle.

Extinction training. During extinction, the stimulus light above the active nose-poke operandum was not illuminated. Responding on either nose-poke operandum was without programmed consequences (i.e., no cocaine infusion and no conditioned tone-light cue). The rats were exposed to extinction training until responding at the active nose-poke operandum decreased to below $20 \%$ of the mean responding during the last $3 \mathrm{~d}$ of cocaine self-administration for at least 2 consecutive days.

Reinstatement test for cocaine seeking. Once responding on the active nose-poke operandum was successfully extinguished according to the criteria described above, reinstatement testing commenced. The testing conditions were the same as during training, with the exception that active nose pokes were not reinforced with cocaine. Each session began with illumination of the house light, which remained on for the entire session. Nose-poke responding during the test sessions resulted in contingent presentations of the tone-light cue that was paired previously with cocaine infusions.

\section{Specific experiments}

Experiment 1: effect of cue-induced reinstatement on NAc p70s6k/rps6 activity. To assess the effect of cocaine-associated discrete cue exposure on p70s6k/rps6 activity in the NAc core and shell, four groups of rats were used ( $n=6-8$ per group) in a 2 (drug condition: saline and cocaine) $\times$
2 (cue exposure: no and yes) experimental design: (1) rats had access to saline self-administration but were not subjected to cue exposure (saline-no test group), (2) rats had access to saline self-administration and were subjected to cue exposure (saline-test group), (3) rats had access to cocaine self-administration but were not subjected to cue exposure (cocaine-no test group), and (4) rats had access to cocaine self-administration and were subjected to cue exposure (cocaine-test group). The dependent measures were the responses on the active and inactive nose-poke operandi and p70s6k and rps6 levels in the NAc core and shell. After the end of the 30 min cue-induced reinstatement test, all rats were decapitated, and their brains were extracted for subsequent determination of p70s6k and rps6 in the NAc core and shell using Western blotting (see Fig. 2).

Experiment 2: effect of inhibition of NAc p70s6k/rps6 activity on cueinduced reinstatement of cocaine seeking. The purpose of this experiment was to investigate whether p70s6k/rps6 inhibition in the NAc reduces the increased drug seeking induced by drug-related cues. Six groups of rats ( $n=8-10$ per group) received vehicle $(0.5 \mu \mathrm{l} / \mathrm{side})$ or rapamycin (50 $\mu \mathrm{g} / \mathrm{side}$ ) microinjections into the NAc core or shell $30 \mathrm{~min}$ before the cue-induced reinstatement test. The dependent measures were the responses on the active nose-poke operandum and p70s6k and rps6 levels in the NAc core and shell. After the end of the $30 \mathrm{~min}$ cue-induced reinstatement test, all rats were decapitated, and their brains were extracted for subsequent determination of p70s6k and rps6 in the NAc core and shell using Western blotting (see Figs. 3, 4).

Experiment 3: effect of activation of NAc core p70s6k/rps6 activity on cue-induced reinstatement of cocaine seeking. To determine the effect of activation of p70s6k/rps6 activity in the NAc core on cue-induced reinstatement of cocaine seeking, three groups of rats $(n=6-8$ per group) were trained for cocaine self-administration. After extinction, rats received NMDA microinjections $(0,25$, and $250 \mathrm{ng} /$ side $)$ into the NAc core $5 \mathrm{~min}$ before the cue-induced reinstatement test. The dependent measures were the responses on the active nose-poke operandum and p70s6k and rps6 levels in the NAc core and shell. After the end of the $30 \mathrm{~min}$ cue-induced reinstatement test, all rats were decapitated, and their brains were extracted for subsequent determination of p70s6k and rps6 in the NAc core and shell using Western blotting (see Fig. 5).

Experiment 4: effect of inhibition of NAc core p $70 \mathrm{~s} 6 \mathrm{k} / \mathrm{rps} 6$ activity on the increased cue-induced reinstatement of drug seeking induced by NMDA. We subsequently determined whether the increase in cue-induced reinstatement of drug seeking induced by NAc microinjection of NMDA is dependent on p70s6k/rps6 activation. Four groups of rats $(n=8-10$ per group) in a 2 (NMDA dose: 0 and $250 \mathrm{ng} /$ side) $\times 2$ (rapamycin dose: 0 and $50 \mu \mathrm{g} / \mathrm{side}$ ) factorial design were used. Rapamycin or its vehicle was injected $30 \mathrm{~min}$ before the reinstatement test. NMDA or its vehicle was injected $5 \mathrm{~min}$ before the reinstatement test. The dependent measures were the responses on the active nose-poke operandum and p70s6k and rps6 levels in the NAc core and shell. After the end of the 30 min cueinduced reinstatement test, all rats were decapitated, and their brains were extracted for subsequent determination of p70s6k and rps6 in the NAc core and shell using Western blotting (see Fig. 6).

Experiment 5: effect of inhibition of NAc p70s6k/rps6 activity on cocaine self-administration training. Because some pharmacological manipulations impair drug intake during cocaine self-administration training, we determined whether inhibition NAc p70s6k/rps6 activity affects cocaine intake. Four groups of rats received microinjections of rapamycin or its vehicle into the NAc core or shell after stable cocaine self-administration behavior was achieved over $10 \mathrm{~d}$ ( $n=7-10$ per group). On day 11, rapamycin or its vehicle was microinjected into the NAc core or shell. Rats then underwent three test sessions that were the same as the selfadministration session. Rapamycin or its vehicle was injected $30 \mathrm{~min}$ before the first test. The dependent measures were cocaine infusions during the 8-10 self-administration days and the test days (see Fig. 7).

Experiment 6: effect of $N A c p 70 s 6 \mathrm{k} / \mathrm{rps} 6$ inhibition on cue-induced reinstatement of sucrose seeking. In this experiment, we determined whether NAc p70s6k/rps6 inhibition affects cue-induced reinstatement of sucrose seeking. Four groups of rats ( $n=7-10$ per group) that were trained for oral sucrose self-administration received microinjections of rapamycin or its vehicle into the NAc core or shell before the cue-induced reinstatement test (see Fig. 8). 
Statistical analyses

Data from the reinstatement test sessions were analyzed separately for total active and inactive nose-poke responses. Nose-poke responding, phosphorylated p70s6k, total p70s6k, phosphorylated rps6, and total rps6 were analyzed using ANOVA with the appropriate between- and within-subjects factors for the different experiments (see Results). Post hoc analyses of significant effects in the ANOVA were performed using the Turkey's test. Values of $p<0.05$ were considered statistically significant.

\section{Results}

Drug-related cue exposure induced reinstatement of cocaine seeking and activated the mTOR signaling pathway

In experiment 1 , we used four groups of rats in a 2 (reward type: saline and cocaine) $\times 2$ (reinstatement test: no test and test) factorial design to test the effect of exposure to cocaine cues on cocaine seeking and p70s6k/rps6 activity in the NAc core and shell. Similar to previous studies, the number of nose-poke responses after exposure to cocaine-related cues was higher than after extinction from cocaine (Fig. $2 a$ ). We analyzed the number of active and inactive nose-poke responses using ANOVA, with the between-subjects factors reward type and reinstatement test. The statistical analysis revealed significant effects of reward type $\left(F_{(2,34)}=6.10, p<0.05\right)$ and reinstatement test $\left(F_{(2,34)}=22.21\right.$, $p<0.01)$ and a significant reinstatement test $\times$ reward type interaction for responses on the active $\left(F_{(4,34)}=8.20, p<0.01\right)$ but not inactive $(p>0.05)$ nose-poke operandum. Post hoc analysis showed that the number of active nose pokes during the cue-induced reinstatement test after extinction from cocaine was higher than the other groups. For all groups, the number of presses on the inactive nose-poke operandum (i.e., a nose poke that was not associated previously with cocaine or saline infusions) was very low (Fig. $2 b$ ).

Exposure to cocaine cues after extinction induced selective increases in phosphorylated, but not total, p70s6k and rps6 in the NAc core (Fig. $2 c-f$ ). Data analyses from the Western blot assay were performed separately for the NAc core and shell and included the between-subjects factors reward type and reinstatement test. The statistical analysis for both p70s6k and rps6 revealed significant reinstatement test $\times$ reward type interactions (p70s6k: $F_{(1,24)}=4.52, p<0.05 ;$ rps6: $\left.F_{(1,24)}=4.59, p<0.05\right)$. In the NAc core, a subsequent one-way ANOVA revealed an effect of experimental group $\left(F_{(3,24)}=4.72, p<0.05\right)$, and post hoc analysis showed that phosphorylated p70s6k and rps6 levels in rats in the cocaine-trained group exposed to the cocaine cues were higher than those of the other groups (Fig. $2 c, d$ ). However, no significant difference between phosphorylated p70s6k and rps6 levels in the NAc shell was observed among groups.

\section{NAc core but not shell mTOR inhibition attenuated cue-induced reinstatement of cocaine seeking} In experiment 2, we determined the functional role of NAc mTOR pathway activation in the enhanced cocaine seeking induced by cue exposure after extinction. For this purpose, we infused rapamycin, which inhibits p70s6k phosphorylation, or its vehicle (20\% DMSO) into the NAc core or shell 30 min before the reinstatement tests. Western blot assays showed that intra-NAc core infusions of rapamycin decreased phosphorylated p70s6k $\left(F_{(2,29)}=11.13, p<0.05\right)$ and $\operatorname{rps} 6\left(F_{(2,29)}=4.15, p<0.05\right)$ in the NAc core but not shell (p70s6k: $F_{(2,29)}=0.85, p>0.5$; rps6: $F_{(2,29)}=0.14, p>0.5$ ) (Fig. $\left.3 a, b\right)$. NAc core infusions of rapamycin decreased responding on the active nose-poke operandum in the reinstatement test (Fig. $3 c$ ). The statistical analysis revealed significant effects of cue exposure $\left(F_{(1,39)}=59.51, p<0.001\right)$ and

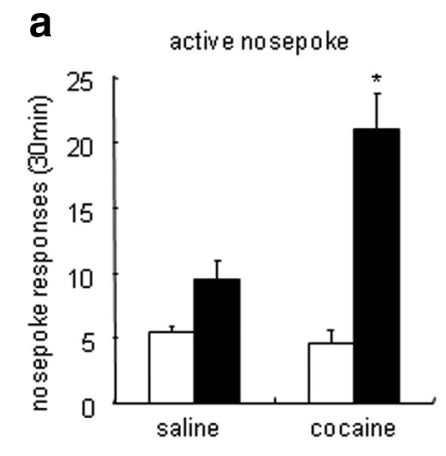

b inactive nosepoke

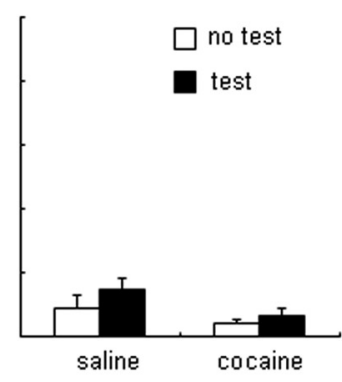

C

phosphorylated p70s6k

d phosphorylated s6
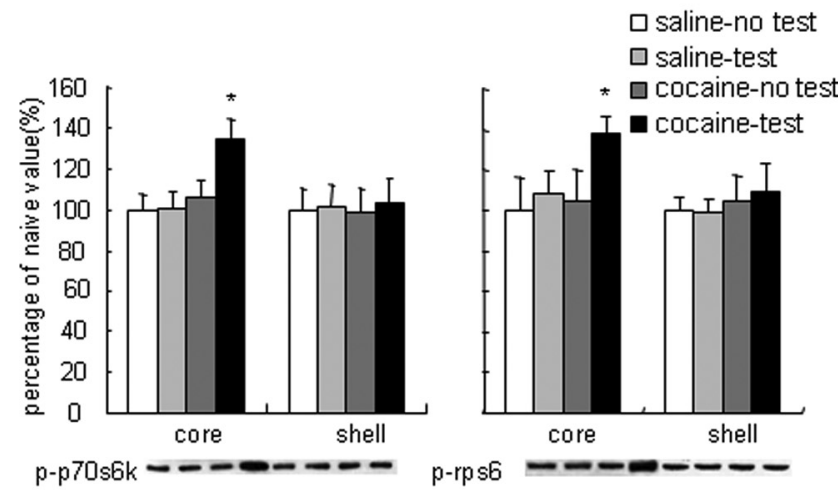

e

total $\mathrm{p} 70 \mathrm{~s} 6 \mathrm{k}$

f

total rps6
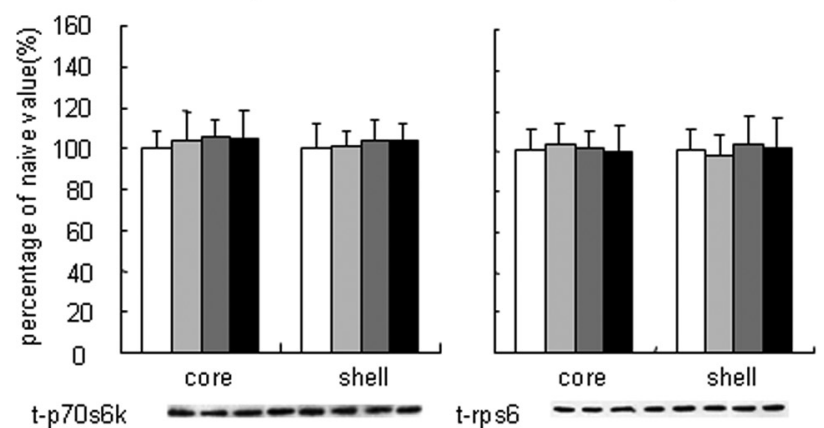

t-rps6

Figure 2. Exposure to drug-related cues reinstated cocaine-seeking behavior and increased p70s6k and rps6 phosphorylation in the NAc core. Data are expressed as mean \pm SEM. $\boldsymbol{a}$, Number of responses on active nose-poke operandum (previously associated with saline or cocaine infusions during the training phase). $\boldsymbol{b}$, Number of responses on inactive nose-poke operandum. Rats in the test condition were trained to self-administer cocaine or saline and were exposed to the cocaine or saline cues in a 30 min reinstatement test session after extinction (saline-test group and cocaine-test group). Rats in the "no test" condition were trained to self-administer cocaine or saline and were not exposed to the cocaine or saline cues (saline-no test group and cocaine-no test group). c, Percentage of phosphorylated p70s6 in the NAc core and shell. $\boldsymbol{d}$, Percentage of phosphorylated rps 6 in the NAc core and shell. $\boldsymbol{e}$, Percentage of total p70s6k in the NAc core and shell. $\boldsymbol{f}$, Percentage of total rps 6 in the NAc core and shell. Data are expressed as a percentage of the values obtained for the rats infused with vehicle. ${ }^{*} p<0.05$, different from other experimental groups ( $n=6-8$ per group). p, Phosphorylated; t, total.

rapamycin dose $\left(F_{(2,39)}=11.852, p<0.001\right)$ and a significant cue exposure $\times$ rapamycin dose interaction $\left(F_{(2,39)}=11.09, p<\right.$ $0.001)$ for active nose-poke responding. NAc shell infusions of rapamycin decreased phosphorylated p70s6k $\left(F_{(2,26)}=4.907\right.$, $p<0.05)$ and $\operatorname{rps} 6\left(F_{(2,26)}=4.99, p<0.05\right)$ in the NAc shell but not core (p70s6k: $F_{(2,26)}=0.216, p>0.5 ;$ rps6: $F_{(2,26)}=0.85, p>$ 0.5 ) (Fig. $4 a, b$ ). Increased active nose-poke responding was observed after cue exposure in rats that received rapamycin infusion 


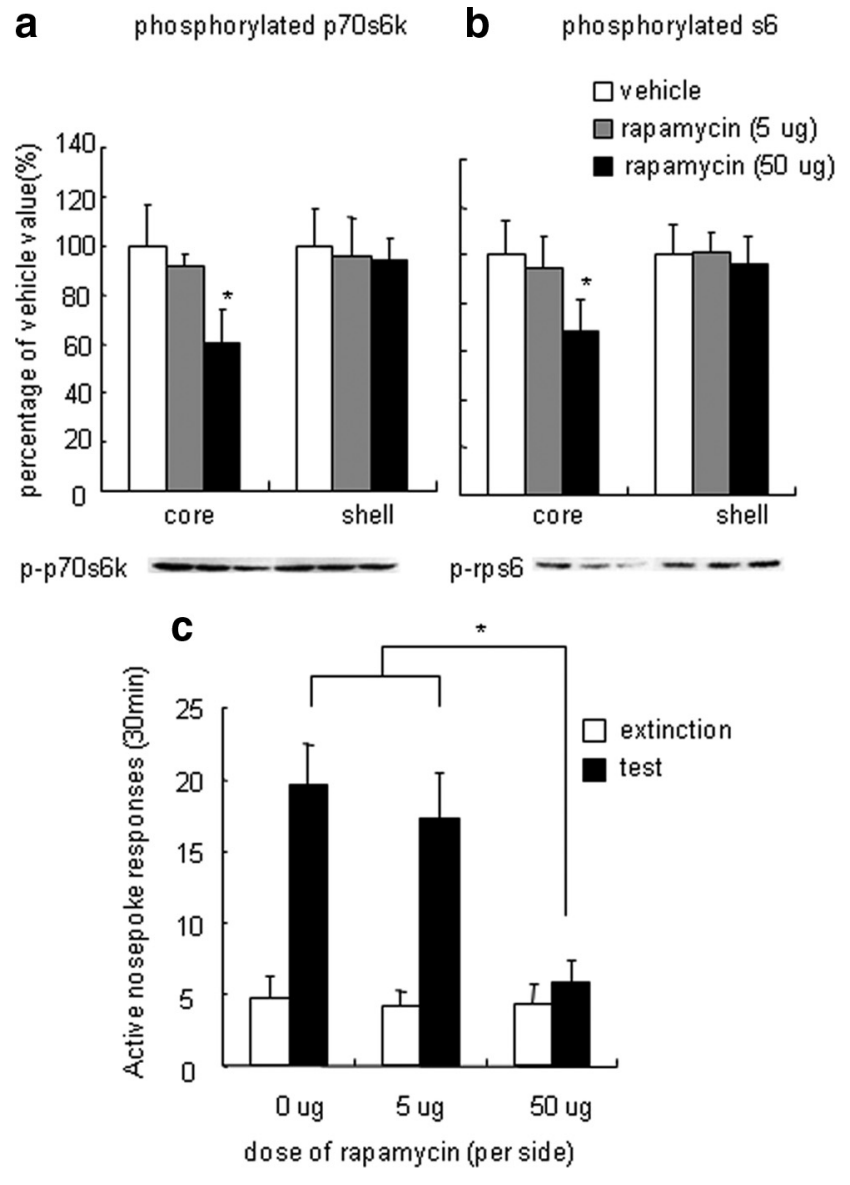

Figure 3. Inhibition of p70s6k-rps6 phosphorylation in the NAc core decreased cue-induced reinstatement of cocaine seeking. $\boldsymbol{a}, \boldsymbol{b}$, Percentage of phosphorylated p70s6k $(\boldsymbol{a})$ and $\operatorname{rps} 6(\boldsymbol{b})$ in the NAc core and shell after infusions of rapamycin into the NAc core 30 min before the reinstatement tests. Data are expressed as a percentage of the values obtained for rats infused with vehicle. $c$, Number of responses (mean \pm SEM) on the active nose-poke operandum after infusions of rapamycin (an inhibitor of p70s6k phosphorylation) or its vehicle (20\% DMSO) into the NAc core 30 min before the reinstatement tests that were conducted after extinction. ${ }^{*} p<$ 0.05 , different from vehicle condition ( $n=8-10$ per group).

in the NAc shell $\left(F_{(1,35)}=78.29, p<0.001\right)$. However, NAc shell infusions of rapamycin had no effect on responding on the active nose-poke operandum in the reinstatement test $\left(F_{(2,35)}=0.002\right.$, $p>0.5$ ) (Fig. 4c). Additionally, no cue exposure $\times$ rapamycin dose interaction was observed $\left(F_{(2,35)}=0.079, p>0.5\right)$. Rapamycin infusions had no effect on inactive nose-poke responding in the reinstatement test or total p70s6k/rps6 expression (data not shown).

\section{NAc core activation of the mTOR pathway enhanced cocaine} seeking during cue-induced reinstatement

The increase in phosphorylated p70s6k in the NAc core after exposure to cocaine cues during the reinstatement test may be mediated by increases in glutamate transmission. Glutamate is known to activate the mTOR pathway through its action on the NMDA receptor (Lenz and Avruch, 2005). This possibility was assessed in experiment 3 in three groups of rats by infusing $\operatorname{NMDA}(0,25$, and $250 \mathrm{ng} / \mathrm{side})$, an agonist of the NMDA receptor, into the NAc core $5 \mathrm{~min}$ before the reinstatement tests. The simple ANOVA included the between-subjects factor NMDA dose $(0,25$, and $250 \mathrm{ng} /$ side $)$. Western blot assays showed that intra-NAc core infusions of NMDA dose dependently increased phosphorylated p70s6k $\left(F_{(2,21)}=15.37, p<0.05\right)$ and rps6

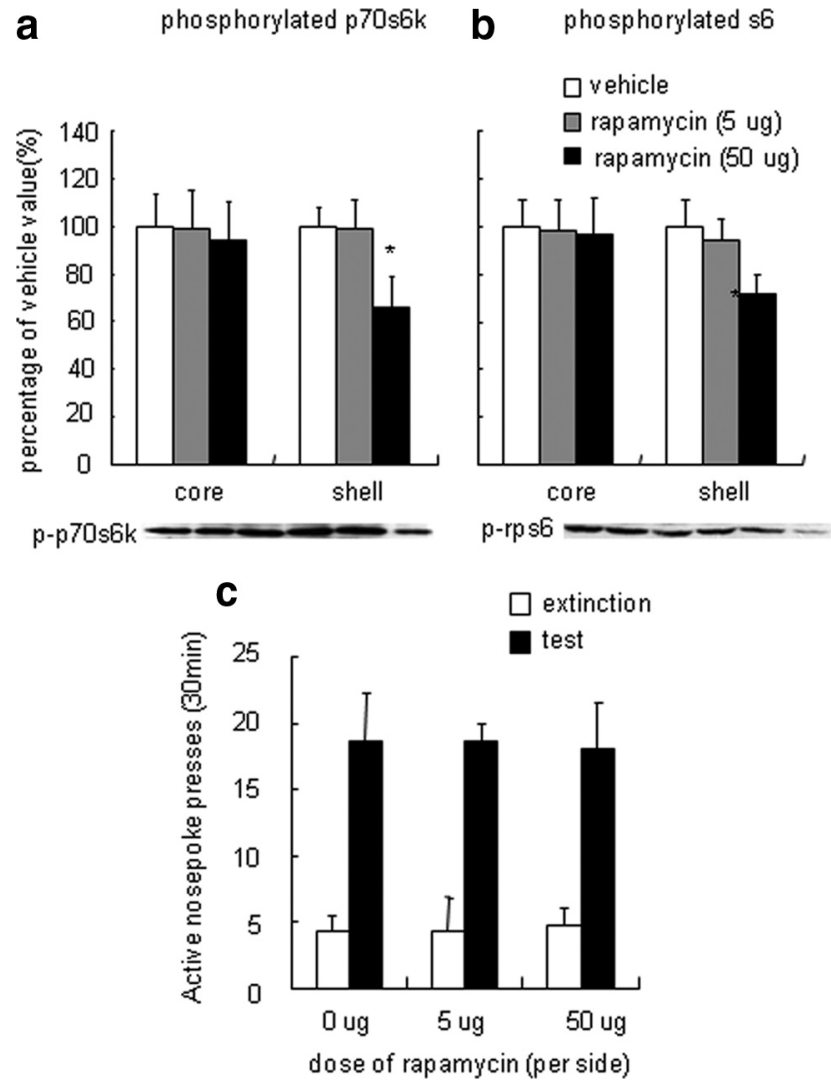

Figure 4. Inhibition of p70s6k-rps6 phosphorylation in the NAc shell did not alter cue-induced cocaine seeking. $\boldsymbol{a}, \boldsymbol{b}$, Percentage of phosphorylated p70s6k (a) and rps6 (b) in the NAc core and shell after infusions of rapamycin into the NAc shell $30 \mathrm{~min}$ before the reinstatement tests. Data are expressed as a percentage of the values obtained for rats infused with vehicle. c, Number of responses (mean \pm SEM) on the active nose-poke operandum after infusions of rapamycin (an inhibitor of p70s6k phosphorylation) or its vehicle (DMSO) into the NAc shell 30 min before the reinstatement tests that were conducted after extinction. ${ }^{*} p<0.05$, different from vehicle condition $(n=8-10$ per group).

$\left(F_{(2,21)}=9.22, p<0.05\right)$ in the NAc core but not shell (p70s6k: $F_{(2,21)}=0.24, p>0.5$; rps6: $\left.F_{(2,21)}=0.34, p>0.5\right)($ Fig. $5 a, b)$. NMDA infusions had no effect on total p70s6k or rps6 level (data not shown). NAc core infusions of NMDA dose dependently increased responding on the active nose-poke operandum in the reinstatement test (Fig. $5 c$ ). The statistical analysis revealed a significant effect of cue exposure $\left(F_{(1,43)}=326.26, p<0.001\right)$ and NMDA dose $\left(F_{(2,43)}=8.15, p<0.05\right)$ and a significant cue exposure $\times$ NMDA dose interaction $\left(F_{(2,43)}=8.15, p<0.05\right)$ for active nose-poke responding. NMDA infusions had no effect on inactive nose-poke responding in any of the groups (data not shown).

In experiment 4 , to further determine the role of the mTOR pathway in the NAc core in the reinstatement of cocaine seeking, NMDA and rapamycin were infused into the NAc core. Pretreatment with rapamycin in the NAc core attenuated NMDAinduced increases in responding on the active lever (Fig. $6 c$ ). Data were analyzed using the factors NMDA dose ( 0 and $250 \mathrm{ng} / \mathrm{side})$ and rapamycin dose ( 0 and $50 \mu \mathrm{g} /$ side $)$. This analysis revealed an NMDA dose $\times$ rapamycin dose interaction for active $\left(F_{(1,28)}=\right.$ $7.5, p<0.05)$ but not inactive $(p>0.05)$ nose-poke responding. Pretreatment with rapamycin also attenuated NMDA-induced increases in phosphorylated p70s6k and rps6 in the NAc core (Fig. $6 a, b$ ). The statistical analysis revealed significant effects of 

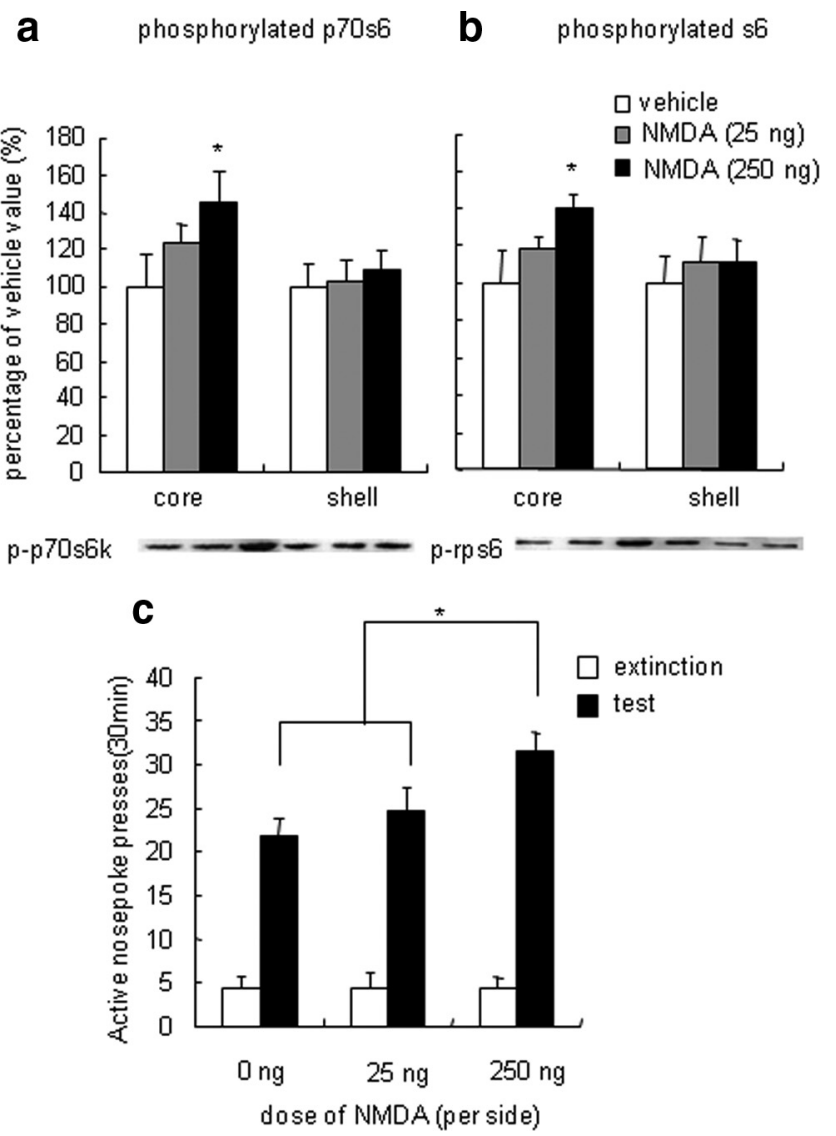

Figure 5. Enhanced p70s6k-rps6 phosphorylation in the NAc core by NMDA increased cue-induced reinstatement of cocaine seeking. $\boldsymbol{a}, \boldsymbol{b}$, Percentage (mean \pm SEM) of phosphorylated p70s6k $(\boldsymbol{a})$ and rps6 $(\boldsymbol{b})$ in the NAc core and shell after infusions of NMDA into the NAc core. Data are expressed as a percentage of the values obtained for rats infused with vehicle. $c$, Number of responses (mean \pm SEM) on the active nose-poke operandum and after infusions of NMDA or its vehicle into the NAc core 5 min before the reinstatement tests that were conducted after extinction. Bilateral infusions of NMDA into the NAc core increased cocaine seeking. ${ }^{*} p<0.05$, different from vehicle and rapamycin $(5 \mu \mathrm{g})$ condition ( $n=6-8$ per group).

NMDA dose (p70s6k: $F_{(1,28)}=34.37, p<0.001$; rps6: $F_{(1,28)}=$ $26.10, p<0.001)$ and rapamycin dose (p70s6k: $F_{(1,28)}=4.48, p<$ 0.05; rps6: $\left.F_{(1,28)}=4.98, p<0.05\right)$. Total p70s6k and rps6 levels were not altered by infusing NMDA, rapamycin, or both (data not shown).

\section{NAc inhibition of the mTOR pathway did not alter cocaine intake}

We determined the specificity of the behavioral effects of NAc infusions of rapamycin on cocaine seeking induced by exposure to the drug cues. In experiment 5, we tested whether these infusions would alter cocaine self-administration. The rats were trained to self-administer cocaine as described above. Rats exhibited stable cocaine infusions during the last 3 self-administration days (days $8-10$ ) with within-subject variability of $<10 \%$ in daily cocaine intake. No differences in the number of infusions during the last $3 \mathrm{~d}$ were observed. On the test day 1 (day 11 ), rats received a bilateral intra-NAc core injection of rapamycin $(50 \mu \mathrm{g} / \mathrm{side})$ or its vehicle (20\% DMSO) $30 \mathrm{~min}$ before the self-administration test session, which was the same as the training session. The test session (tests 2 and 3 ) was repeated for 2 consecutive days (days 12 and 13) without rapamycin infusion. Figure 7 shows the number of cocaine infusions for animals that received intra-NAc core
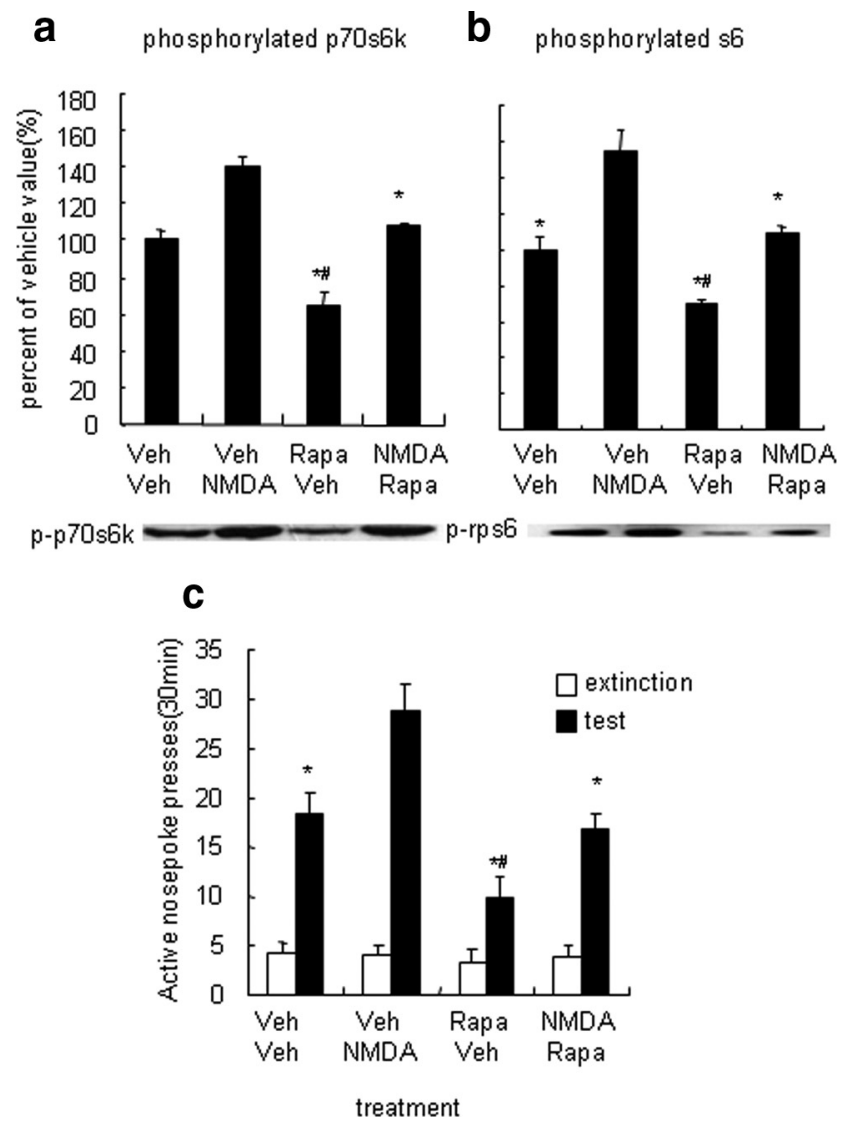

Figure 6. Effects of rapamycin infusions into the NAc core on NMDA-induced increases in reinstatement of cocaine seeking and NMDA-induced increases in p70s6k-rps6 phosphorylation. $\boldsymbol{a}, \boldsymbol{b}$, Percentage (mean \pm SEM) of phosphorylated p70s6k $(\boldsymbol{a})$ and rps $6(\boldsymbol{b})$ in the NAc core after infusions of rapamycin, NMDA, and their vehicles into the NAc core. Data are expressed as a percentage of the values obtained for rats infused with vehicle. $c$, Number of responses (mean \pm SEM) on the active nose-poke operandum after combined infusions of NMDA (250 $\mathrm{ng} / \mathrm{side}$ ), rapamycin (50 $\mu \mathrm{g} / \mathrm{side}$ ), or their vehicles into the NAc core 5 or 30 min before the reinstatement tests that were conducted after extinction. Rapamycin infusions into the NAC core reversed NMDA-induced potentiation of cocaine seeking and NMDA-induced p70s6k and rps6 phosphorylation. ${ }^{*} p<0.05$, different from vehicle-NMDA group. ${ }^{\#} p<0.05$, different from vehicle-vehicle group ( $n=8-10$ per group). Veh, Vehicle (sterile saline for NMDA; DMSO for rapamycin); Rapa, rapamycin.

injections of either rapamycin or its vehicle. No differences in the number of infusions were observed between groups $\left(F_{(1,89)}=\right.$ $0.66, p>0.05)$ during the sessions before or after the injections $\left(F_{(1,89)}=0.99, p>0.05\right)$.

NAc inhibition of the mTOR pathway did not alter cueinduced reinstatement of sucrose seeking

In experiment 6, we determined whether inhibition of the NAc mTOR pathway affects cue-induced reinstatement of sucrose seeking. Rapamycin or its vehicle (20\% DMSO) was infused into the NAc core or shell 30 min before the reinstatement tests. Similar to the cocaine reinstatement experiments, the number of active nose-poke responses after exposure to sucrose-related cues was higher than after extinction from sucrose. However, NAc core or shell infusions of rapamycin did not alter responding on the active nose-poke operandum in the reinstatement test (Fig. $8 a, b)$. The statistical analysis revealed significant effects of cue exposure (core: $F_{(1,35)}=66.55, p<0.001$; shell: $F_{(1,27)}=47.41$, $p<0.001$ ) but not rapamycin dose (core: $F_{(1,35)}=1.42, p>0.05$; shell: $\left.F_{(1,27)}=0.02, p>0.5\right)$ and no significant cue exposure $\times$ 


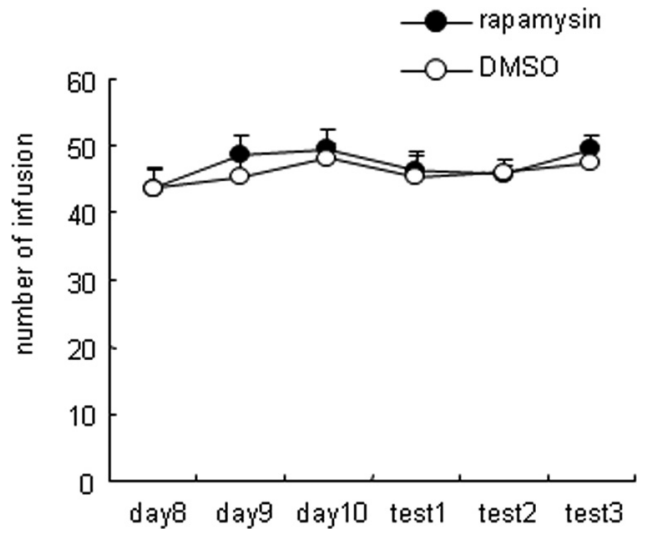

Figure 7. Infusion of rapamycin into the NAc core did not alter cocaine intake during cocaine self-administration training. Number of cocaine infusions $(0.75 \mathrm{mg} / \mathrm{kg}$ per infusion) during the $3 \mathrm{~h}$ training session (mean \pm SEM) before and after bilateral infusions of rapamycin $(50 \mu \mathrm{g} /$ side) or its vehicle ( $20 \%$ DMSO) into the NAc core on the test day after $10 \mathrm{~d}$ of cocaine selfadministration training. Baseline cocaine intake is expressed as the number of cocaine infusions from day 8 to day 10. Rats demonstrated reliable cocaine self-administration during baseline. No difference in cocaine intake was observed between baseline and the test days in any of the groups ( $n=7-10$ per group).
Infusion in NAc core
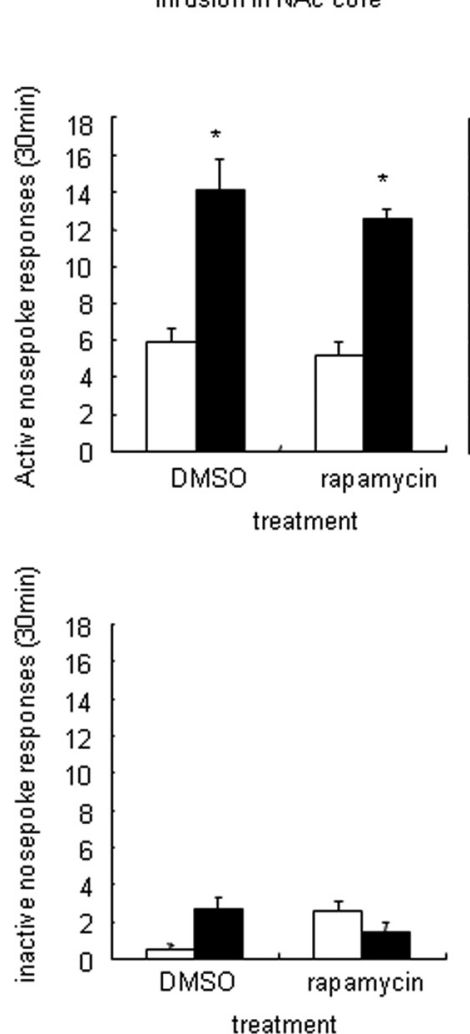

Infusion in NAC shell
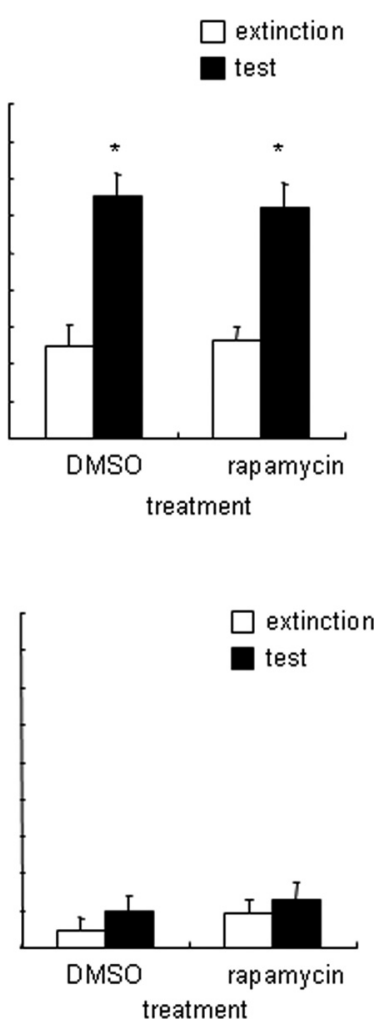

Figure 8. Inhibition of mTOR in NAc core and shell did not alter cue-induced reinstatement of sucrose seeking. Number of responses (mean \pm SEM) on active nose-poke operandum in rats that received infusions of rapamycin or its vehicle (DMSO) into the NAc core (a) and NAc shell ( $\boldsymbol{b}$ ) $30 \mathrm{~min}$ before the reinstatement tests that were conducted after extinction. The figure shows the number of responses (mean \pm SEM) on the inactive nose-poke operandum in rats that received infusions of rapamycin or its vehicle (DMSO) into the NAc core (c) and NAc shell (d) 30 min before the reinstatement tests that were conducted after extinction ( $n=7-10$ per group).

rapamycin dose reward type interaction for responses on the active nose-poke operandum (core: $F_{(1,35)}=0.15, p>0.5 ; F_{(1,27)}=$ $1.42, p>0.5)$. For all groups, the number of responses on the inactive nose-poke operandum was very low (Fig. $8 c, d$ ).

\section{Discussion}

We found that cue-induced reinstatement of cocaine seeking is associated with activation of the mTOR signaling pathway in the NAc core but not shell. Intra-NAc core, but not shell, administration of rapamycin attenuated cue-induced reinstatement of cocaine seeking. The attenuation of cocaine seeking was accompanied by decreases in p70s6k and rps6 phosphorylation. NMDA infusions into the NAc core increased p70s6k and rps6 phosphorylation and augmented cue-induced reinstatement. This effect was blocked by pretreatment with rapamycin in the NAc core. Furthermore, rapamycin infusion into the NAc core did not alter ongoing cocaine self-administration. Finally, rapamycin infusions into either the NAc core or shell had no effect on cueinduced reinstatement of sucrose seeking. These findings suggest that mTOR signaling activation in the NAc core mediates cueinduced reinstatement of cocaine seeking.

The NAc core and shell subregions are differentially involved in the reinstatement of cocaine seeking, depending on the type of trigger that elicits this behavior. Our present results on the role of the NAc core, but not shell, in discrete cue-induced reinstatement of cocaine seeking are consistent with previous findings showing that reversible inactivation (muscimol plus baclofen) of the NAc core attenuated cocaine seeking in cue-induced reinstatement, and NAc shell inactivation failed to alter cocaine seeking (Fuchs et al., 2004). Similarly, inactivation of the NAc core with muscimol plus baclofen injection blocked cue-induced reinstatement of cocaine seeking, but inactivation of the NAc shell increased cue-induced reinstatement of the extinguished response that had previously delivered cocaine (Di Ciano et al., 2008). The present results are also consistent with findings showing that permanent lesions or antagonism of AMPA receptors in the NAc core, but not shell, decreased cue-induced cocaine seeking assessed in a second-order schedule of reinforcement (Di Ciano and Everitt, 2001; Ito et al., 2004). Similar findings were observed with infusions of ionotropic glutamate receptor antagonists (Everitt et al., 2001; Bäckström and Hyytiä, 2006). Injections of the dopamine $\mathrm{D}_{1}$ receptor antagonist SCH 23390 into the NAc core, but not lateral or medial shell, attenuated cue-induced reinstatement of heroin seeking (Bossert et al., 2006). Conversely, SCH $23390[R(+)$ 7-chloro-8-hydroxy-3-methyl-1-phenyl-2,3,4,5-tetrahydro- $1 H$-3benzazepine hydrochloride] injections into the lateral or medial shell, but not core, decreased context-induced reinstatement of heroin seeking (Bossert et al., 2006). These results are consistent with another study showing that medial shell injections of the metabotropic glutamate $2 / 3$ receptor agonist LY379268 $(1 R, 4 R, 5 S, 6 R-2$ oxa-4-aminobicyclo[3.1.0] hexane-4,6-dicarboxylate) decreased context-induced reinstatement of heroin seeking (Bossert et al., 2006). However, another study showed that GABA agonist-induced neural inhibition within the NAc core or shell disrupted contextinduced reinstatement of cocaine seeking (Fuchs et al., 2008). Moreover, exposure to discriminative cues that predicted cocaine availability increased neuronal activity in the shell but not core (Ghitza et al., 2003). Altogether, these results demonstrate that the NAc is a functionally heterogeneous structure with respect to its involvement in cue- and context-induced cocaine seeking.

The NAc core and shell are neuroanatomically dissociable heterogeneous structures with distinct immunohistochemical characteristics and afferent and efferent connections (Voorn et al., 1989; Zahm and Brog, 1992). The NAc core is a part of a larger corticolimbic neural circuitry that receives afferents predominantly from the amygdala (Groenewegen et al., 1999) and dorsomedial prefrontal cortex (Kalivas et al., 2003) and plays an 
important role in the conditioned reinforcing effects of drugrelated cues and the generation of cocaine-seeking behavior (McFarland and Kalivas, 2001; Capriles et al., 2003; McFarland et al., 2003, 2004). Interference with the functional interaction between dopamine-dependent associative processes in the basolateral amygdala and glutamate-dependent processes in the NAc core using bilateral infusions of the $\mathrm{D}_{1 / 2 / 3}$ receptor antagonist $\alpha$-flupenthixol or the AMPA/kainate receptor antagonist LY293558 (3SR, 4aRS, 6RS, 8aRS-6-[2-(iH-tetrazol-5-yl)ethyl]-1,2,3,4,4a,5,6,7,8,8a-decahydroiso-quinoline-3-carboxylic acid), respectively, reduced cuemaintained cocaine seeking (Di Ciano and Everitt, 2004). Conversely, the role of the NAc shell region on behavior in response to contextual cues (Crombag et al., 2008) may derive from its anatomical connections with the hippocampus (Van den Bercken and Cools, 1982; Groenewegen et al., 1987; McDonald and White, 1993; Floresco et al., 2001).

The important role of glutamate transmission in drug-seeking behavior after long-term withdrawal has also been demonstrated. Injection of an NMDA receptor antagonist before the reinstatement test reduced cocaine seeking induced by both cocaine priming and conditioned cue exposure (Bäckström and Hyytiä, 2006, 2007; Feltenstein and See, 2007; Milton et al., 2008; Kelamangalath et al., 2009). A similar effect was observed with cue-induced reinstatement of alcohol seeking (Bachteler et al., 2005; von der Goltz et al., 2009). These data indicate that stimulus-induced motivated behavior is mediated through glutamate neurotransmission. The present results showed that NMDA infusion into the NAc core enhanced cue-induced reinstatement of cocaine seeking by increasing phosphorylation of the downstream mTOR target, which is consistent with previous studies showing that NMDA receptor inactivation in the NAc core reduced reinstatement of cocaine seeking (Bäckström and Hyytiä, 2006, 2007; Feltenstein and See, 2007; Milton et al., 2008). Our results further demonstrate that NAc core activation of the mTOR signaling pathway by stimulation of NMDA receptors is critically involved in reinstatement of cocaine seeking. Furthermore, rapamycin pretreatment blocked the enhanced reinstatement of cocaine seeking induced by NMDA infusion. Altogether, the present results indicate that mTOR signaling pathway activation may be a potential mechanism underlying cue-induced reinstatement.

Exposure to drug-related environment stimuli produces neuroplasticity in the mesolimbic dopamine system through gene expression and protein synthesis, which is one of the main factors leading to relapse. mTOR activity is required for protein synthesis-dependent synaptic changes (Casadio et al., 1999). Our findings corroborate previous reports and demonstrate that mTOR signaling pathway activation in the NAc core is involved in discrete cue-induced reinstatement. The rapamycin-sensitive reinstatement of cue-induced cocaine seeking indicates that mTOR-dependent neural plasticity is required for the process of drug relapse. A main role of the mTOR pathway in synaptic plasticity is to regulate the translation of proteins that make up translational machinery, including various elongation factors and ribosomal proteins (Meyuhas, 2000). Activation of the mTOR pathway specifically increased phosphorylation of its downstream target p70s6k. Therefore, the level of phosphorylated p70s6k and its substrate rps6 can be used to index mTOR activity (Nathan et al., 2004; Martin et al., 2007). Phosphorylated p70s6k further activates rps6 and possibly the translation initiation factor eIF4B, leading to initiation of 5'TOP mRNA translation (van der Velden and Thomas, 1999; Meyuhas, 2000; Raught et al., 2004; Ruvinsky and Meyuhas, 2006). rps6 is a component of the $40 \mathrm{~S}$ ribosomal subunit, and its phosphorylation increased the affinity of the ribosome for 5'TOP mRNA, which may function to boost translational capacity (Tang et al., 2001). The present study demonstrated the molecular involvement of the p70s6krps6 pathway in mTOR-dependent activation of the translational machinery, and this activation leads to protein synthesis after exposure to discrete cues during reinstatement. This mTORdependent translation may contribute to cue-induced reinstatement of cocaine seeking. The maintenance of LTP consists of an early translation-dependent, transcription-independent phase during the initial 60-90 min after induction and a subsequent transcription-dependent phase (Kelleher et al., 2004). Moreover, pretreatment with transcriptional inhibitors produced a delayed effect on the maintenance of LTP, whereas pretreatment with translational inhibitors had an immediate effect (Nguyen et al., 1994; Frey et al., 1996; Frey and Morris, 1997; Scharf et al., 2002). In the present study, rapamycin was infused into the NAc core 30 min before the reinstatement test, and our findings suggest that the translational control induced by blocking the p70s6k-rps6 pathway is involved in the acute effect of rapamycin on reinstatement of cocaine seeking. However, the possibility that mTOR activation affects other translational control cascades cannot be completely excluded. Activation of mTOR enhances capdependent translation by 4EBP1 (phosphorylating eukaryotic initiation factor 4E-binding protein 1) (Isotani et al., 1999) and regulation of the translation during the elongation stage (Wang et al., 2001).

A canonical pathway that regulates mTOR activity begins with activation of receptor tyrosine kinases by mitogens, trophic factors (e.g., brain-derived neurotrophic factor), amino acids, and hormones (e.g., insulin) (Swiech et al., 2008). Additionally, neuron-specific substances such as neurotransmitters can induce mTOR activity (Cammalleri et al., 2003; Hou and Klann, 2004; Lenz and Avruch, 2005). Short- and long-term exposure to glutamatergic stimulation produces, respectively, stimulatory and inhibitory effects on p70S6K, rps6, Akt, and extracellular signalregulated kinase (ERK) phosphorylation, suggesting the importance of a short pulse of glutamatergic stimulation for the activation of these pathways (Lenz and Avruch, 2005). Consistent with our findings showing that rapamycin pretreatment reversed the effect of NMDA on cue-induced reinstatement and mTOR signaling pathway activity, inhibition of mTOR activity with rapamycin blocked dendritic green fluorescent protein synthesis induced by stimulation of NMDA receptors and metabotropic glutamate receptors (Gong et al., 2006). Moreover, inhibition of the mTOR upstream activators phosphatidylinositol 3-kinase (PI3K) and Akt also abolished NMDA receptor-regulated protein synthesis in dendrites, suggesting that NMDA may increase mTOR activity through the PI3K-Akt signaling pathway (Hou and Klann, 2004; Gong et al., 2006). However, this NMDAmTOR signaling pathway likely interacts with other translational signaling cascades to coordinate protein synthesis. For example, inhibition of ERK blocked the phosphorylation of 4EBP1 and ribosomal protein S6 (Kelleher et al., 2004), indicating crosstalk between the mTOR and mitogen-activated protein kinase signaling pathways. Understanding the crosstalk between mTOR and other translational signaling pathways during protein synthesis in cue-induced reinstatement is an issue that will need to be addressed in the future.

\section{Concluding remarks}

Our results indicate that activation of the NAc core mTOR signaling pathway mediates cue-induced reinstatement of cocaine seeking. Drug-induced adaptations in neuronal mechanisms 
have been suggested to be involved in drug relapse and craving. The present findings support this hypothesis and provide new evidence implicating mTOR pathway activation in cue-induced relapse to cocaine seeking.

\section{References}

Bachteler D, Economidou D, Danysz W, Ciccocioppo R, Spanagel R (2005) The effects of acamprosate and neramexane on cue-induced reinstatement of ethanol-seeking behavior in rat. Neuropsychopharmacology 30:1104-1110.

Bäckström P, Hyytiä P (2006) Ionotropic and metabotropic glutamate receptor antagonism attenuates cue-induced cocaine seeking. Neuropsychopharmacology 31:778-786.

Bäckström P, Hyytiä P (2007) Involvement of AMPA/kainate, NMDA, and mGlu5 receptors in the nucleus accumbens core in cue-induced reinstatement of cocaine seeking in rats. Psychopharmacology (Berl) 192:571-580.

Bossert JM, Ghitza UE, Lu L, Epstein DH, Shaham Y (2005) Neurobiology of relapse to heroin and cocaine seeking: an update and clinical implications. Eur J Pharmacol 526:36-50.

Bossert JM, Gray SM, Lu L, Shaham Y (2006) Activation of group II metabotropic glutamate receptors in the nucleus accumbens shell attenuates context-induced relapse to heroin seeking. Neuropsychopharmacology 31:2197-2209.

Bossert JM, Poles GC, Wihbey KA, Koya E, Shaham Y (2007) Differential effects of blockade of dopamine $\mathrm{D}_{1}$-family receptors in nucleus accumbens core or shell on reinstatement of heroin seeking induced by contextual and discrete cues. J Neurosci 27:12655-12663.

Cammalleri M, Lütjens R, Berton F, King AR, Simpson C, Francesconi W, Sanna PP (2003) Time-restricted role for dendritic activation of the mTOR-p70S6K pathway in the induction of late-phase long-term potentiation in the CA1. Proc Natl Acad Sci U S A 100:14368-14373.

Capriles N, Rodaros D, Sorge RE, Stewart J (2003) A role for the prefrontal cortex in stress- and cocaine-induced reinstatement of cocaine seeking in rats. Psychopharmacology (Berl) 168:66-74.

Casadio A, Martin KC, Giustetto M, Zhu H, Chen M, Bartsch D, Bailey CH, Kandel ER (1999) A transient, neuron-wide form of CREB-mediated long-term facilitation can be stabilized at specific synapses by local protein synthesis. Cell 99:221-237.

Childress AR, Mozley PD, McElgin W, Fitzgerald J, Reivich M, O’Brien CP (1999) Limbic activation during cue-induced cocaine craving. Am J Psychiatry 156:11-18.

Crombag HS, Bossert JM, Koya E, Shaham Y (2008) Review. Contextinduced relapse to drug seeking: a review. Philos Trans R Soc Lond B Biol Sci 363:3233-3243.

Dash PK, Orsi SA, Moore AN (2006) Spatial memory formation and memory-enhancing effect of glucose involves activation of the tuberous sclerosis complex-mammalian target of rapamycin pathway. J Neurosci 26:8048-8056.

Di Ciano P, Everitt BJ (2001) Dissociable effects of antagonism of NMDA and AMPA/KA receptors in the nucleus accumbens core and shell on cocaine-seeking behavior. Neuropsychopharmacology 25:341-360.

Di Ciano P, Everitt BJ (2004) Direct interactions between the basolateral amygdala and nucleus accumbens core underlie cocaine-seeking behavior by rats. J Neurosci 24:7167-7173.

Di Ciano P, Robbins TW, Everitt BJ (2008) Differential effects of nucleus accumbens core, shell, or dorsal striatal inactivations on the persistence, reacquisition, or reinstatement of responding for a drug-paired conditioned reinforcer. Neuropsychopharmacology 33:1413-1425.

Epstein DH, Preston KL, Stewart J, Shaham Y (2006) Toward a model of drug relapse: an assessment of the validity of the reinstatement procedure. Psychopharmacology (Berl) 189:1-16.

Everitt BJ, Dickinson A, Robbins TW (2001) The neuropsychological basis of addictive behaviour. Brain Res Brain Res Rev 36:129-138.

Feltenstein MW, See RE (2007) NMDA receptor blockade in the basolateral amygdala disrupts consolidation of stimulus-reward memory and extinction learning during reinstatement of cocaine-seeking in an animal model of relapse. Neurobiol Learn Mem 88:435-444.

Floresco SB, Todd CL, Grace AA (2001) Glutamatergic afferents from the hippocampus to the nucleus accumbens regulate activity of ventral tegmental area dopamine neurons. J Neurosci 21:4915-4922.

Frey U, Morris RG (1997) Synaptic tagging and long-term potentiation. Nature 385:533-536.
Frey U, Frey S, Schollmeier F, Krug M (1996) Influence of actinomycin D, a RNA synthesis inhibitor, on long-term potentiation in rat hippocampal neurons in vivo and in vitro. J Physiol 490:703-711.

Fuchs RA, Evans KA, Parker MC, See RE (2004) Differential involvement of the core and shell subregions of the nucleus accumbens in conditioned cue-induced reinstatement of cocaine seeking in rats. Psychopharmacology (Berl) 176:459-465.

Fuchs RA, Ramirez DR, Bell GH (2008) Nucleus accumbens shell and core involvement in drug context-induced reinstatement of cocaine seeking in rats. Psychopharmacology (Berl) 200:545-556.

Gawin F, Kleber H (1986) Pharmacologic treatments of cocaine abuse. Psychiatr Clin North Am 9:573-583.

Ghitza UE, Fabbricatore AT, Prokopenko V, Pawlak AP, West MO (2003) Persistent cue-evoked activity of accumbens neurons after prolonged abstinence from self-administered cocaine. J Neurosci 23:7239-7245.

Gingras AC, Raught B, Sonenberg N (2001) Control of translation by the target of rapamycin proteins. Prog Mol Subcell Biol 27:143-174.

Gong R, Park CS, Abbassi NR, Tang SJ (2006) Roles of glutamate receptors and the mammalian target of rapamycin (mTOR) signaling pathway in activity-dependent dendritic protein synthesis in hippocampal neurons. J Biol Chem 281:18802-18815.

Groenewegen HJ, Vermeulen-Van der Zee E, te Kortschot A, Witter MP (1987) Organization of the projections from the subiculum to the ventral striatum in the rat. A study using anterograde transport of Phaseolus vulgaris leucoagglutinin. Neuroscience 23:103-120.

Groenewegen HJ, Galis-de Graaf Y, Smeets WJ (1999) Integration and segregation of limbic cortico-striatal loops at the thalamic level: an experimental tracing study in rats. J Chem Neuroanat 16:167-185.

Hou L, Klann E (2004) Activation of the phosphoinositide 3-kinase-Aktmammalian target of rapamycin signaling pathway is required for metabotropic glutamate receptor-dependent long-term depression. J Neurosci 24:6352-6361.

Isotani S, Hara K, Tokunaga C, Inoue H, Avruch J, Yonezawa K (1999) Immunopurified mammalian target of rapamycin phosphorylates and activates p70 S6 kinase alpha in vitro. J Biol Chem 274:34493-34498.

Ito R, Robbins TW, Everitt BJ (2004) Differential control over cocaineseeking behavior by nucleus accumbens core and shell. Nat Neurosci 7:389-397.

Kalivas PW, McFarland K, Bowers S, Szumlinski K, Xi ZX, Baker D (2003) Glutamate transmission and addiction to cocaine. Ann N Y Acad Sci 1003:169-175.

Kelamangalath L, Seymour CM, Wagner JJ (2009) D-serine facilitates the effects of extinction to reduce cocaine-primed reinstatement of drugseeking behavior. Neurobiol Learn Mem 92:544-551.

Kelleher RJ 3rd, Govindarajan A, Jung HY, Kang H, Tonegawa S (2004) Translational control by MAPK signaling in long-term synaptic plasticity and memory. Cell 116:467-479.

Kruzich PJ, See RE (2001) Differential contributions of the basolateral and central amygdala in the acquisition and expression of conditioned relapse to cocaine-seeking behavior. J Neurosci 21:RC155(1-5).

Lenz G, Avruch J (2005) Glutamatergic regulation of the p70S6 kinase in primary mouse neurons. J Biol Chem 280:38121-38124.

Li YQ, Li FQ, Wang XY, Wu P, Zhao M, Xu CM, Shaham Y, Lu L (2008) Central amygdala extracellular signal-regulated kinase signaling pathway is critical to incubation of opiate craving. J Neurosci 28:13248-13257.

Lu L, Grimm JW, Shaham Y, Hope BT (2003) Molecular neuroadaptations in the accumbens and ventral tegmental area during the first 90 days of forced abstinence from cocaine self-administration in rats. J Neurochem 85:1604-1613.

Lu L, Dempsey J, Liu SY, Bossert JM, Shaham Y (2004) A single infusion of brain-derived neurotrophic factor into the ventral tegmental area induces long-lasting potentiation of cocaine seeking after withdrawal. J Neurosci 24:1604-1611.

Lu L, Hope BT, Dempsey J, Liu SY, Bossert JM, Shaham Y (2005) Central amygdala ERK signaling pathway is critical to incubation of cocaine craving. Nat Neurosci 8:212-219.

Lu L, Wang X, Wu P, Xu C, Zhao M, Morales M, Harvey BK, Hoffer BJ, Shaham Y (2009) Role of ventral tegmental area glial cell line-derived neurotrophic factor in incubation of cocaine craving. Biol Psychiatry 66:137-145.

Martin KA, Merenick BL, Ding M, Fetalvero KM, Rzucidlo EM, Kozul CD, Brown DJ, Chiu HY, Shyu M, Drapeau BL, Wagner RJ, Powell RJ (2007) 
Rapamycin promotes vascular smooth muscle cell differentiation through insulin receptor substrate-1/phosphatidylinositol 3-kinase/Akt2 feedback signaling. J Biol Chem 282:36112-36120.

McDonald RJ, White NM (1993) A triple dissociation of memory systems: hippocampus, amygdala, and dorsal striatum. Behav Neurosci 107:3-22.

McFarland K, Kalivas PW (2001) The circuitry mediating cocaine-induced reinstatement of drug-seeking behavior. J Neurosci 21:8655-8663.

McFarland K, Lapish CC, Kalivas PW (2003) Prefrontal glutamate release into the core of the nucleus accumbens mediates cocaine-induced reinstatement of drug-seeking behavior. J Neurosci 23:3531-3537.

McFarland K, Davidge SB, Lapish CC, Kalivas PW (2004) Limbic and motor circuitry underlying footshock-induced reinstatement of cocaine-seeking behavior. J Neurosci 24:1551-1560.

Meil WM, See RE (1997) Lesions of the basolateral amygdala abolish the ability of drug associated cues to reinstate responding during withdrawal from self-administered cocaine. Behav Brain Res 87:139-148.

Meyuhas O (2000) Synthesis of the translational apparatus is regulated at the translational level. Eur J Biochem 267:6321-6330.

Milton AL, Lee JL, Butler VJ, Gardner R, Everitt BJ (2008) Intra-amygdala and systemic antagonism of NMDA receptors prevents the reconsolidation of drug-associated memory and impairs subsequently both novel and previously acquired drug-seeking behaviors. J Neurosci 28:8230-8237.

Nathan CO, Amirghahari N, Abreo F, Rong X, Caldito G, Jones ML, Zhou H, Smith M, Kimberly D, Glass J (2004) Overexpressed eIF4E is functionally active in surgical margins of head and neck cancer patients via activation of the Akt/mammalian target of rapamycin pathway. Clin Cancer Res 10:5820-5827.

Nguyen PV, Abel T, Kandel ER (1994) Requirement of a critical period of transcription for induction of a late phase of LTP. Science 265:1104-1107.

O’Brien CP (1997) A range of research-based pharmacotherapies for addiction. Science 278:66-70.

O'Brien CP, Childress AR, Ehrman R, Robbins SJ (1998) Conditioning factors in drug abuse: can they explain compulsion? J Psychopharmacol 12:15-22.

Parsons RG, Gafford GM, Helmstetter FJ (2006) Translational control via the mammalian target of rapamycin pathway is critical for the formation and stability of long-term fear memory in amygdala neurons. J Neurosci 26:12977-12983.

Proud CG (2007) Cell signaling. mTOR, unleashed. Science 318:926-927.

Raught B, Peiretti F, Gingras AC, Livingstone M, Shahbazian D, Mayeur GL, Polakiewicz RD, Sonenberg N, Hershey JW (2004) Phosphorylation of eucaryotic translation initiation factor 4B Ser422 is modulated by S6 kinases. EMBO J 23:1761-1769.

Ruvinsky I, Meyuhas O (2006) Ribosomal protein S6 phosphorylation: from protein synthesis to cell size. Trends Biochem Sci 31:342-348.

Sabatini DM, Lai MM, Snyder SH (1997) Neural roles of immunophilins and their ligands. Mol Neurobiol 15:223-239.

Scharf MT, Woo NH, Lattal KM, Young JZ, Nguyen PV, Abel T (2002) Protein synthesis is required for the enhancement of long-term potentiation and long-term memory by spaced training. J Neurophysiol $87: 2770-2777$.

See RE (2002) Neural substrates of conditioned-cued relapse to drugseeking behavior. Pharmacol Biochem Behav 71:517-529.
See RE (2005) Neural substrates of cocaine-cue associations that trigger relapse. Eur J Pharmacol 526:140-146.

Shaham Y, Funk D, Erb S, Brown TJ, Walker CD, Stewart J (1997) Corticotropin-releasing factor, but not corticosterone, is involved in stress-induced relapse to heroin-seeking in rats. J Neurosci 17:2605-2614.

Shaham Y, Shalev U, Lu L, De Wit H, Stewart J (2003) The reinstatement model of drug relapse: history, methodology and major findings. Psychopharmacology (Berl) 168:3-20.

Steward O, Schuman EM (2003) Compartmentalized synthesis and degradation of proteins in neurons. Neuron 40:347-359.

Swiech L, Perycz M, Malik A, Jaworski J (2008) Role of mTOR in physiology and pathology of the nervous system. Biochim Biophys Acta 1784:116132 .

Takei N, Inamura N, Kawamura M, Namba H, Hara K, Yonezawa K, Nawa H (2004) Brain-derived neurotrophic factor induces mammalian target of rapamycin-dependent local activation of translation machinery and protein synthesis in neuronal dendrites. J Neurosci 24:9760-9769.

Tang H, Hornstein E, Stolovich M, Levy G, Livingstone M, Templeton D, Avruch J, Meyuhas O (2001) Amino acid-induced translation of TOP mRNAs is fully dependent on phosphatidylinositol 3-kinase-mediated signaling, is partially inhibited by rapamycin, and is independent of S6K1 and rpS6 phosphorylation. Mol Cell Biol 21:8671-8683.

Tang SJ, Reis G, Kang H, Gingras AC, Sonenberg N, Schuman EM (2002) A rapamycin-sensitive signaling pathway contributes to long-term synaptic plasticity in the hippocampus. Proc Natl Acad Sci U S A 99:467-472.

Van den Bercken JH, Cools AR (1982) Evidence for a role of the caudate nucleus in the sequential organization of behavior. Behav Brain Res 4:319-327.

van der Velden AW, Thomas AA (1999) The role of the $5^{\prime}$ untranslated region of an mRNA in translation regulation during development. Int J Biochem Cell Biol 31:87-106.

von der Goltz C, Vengeliene V, Bilbao A, Perreau-Lenz S, Pawlak CR, Kiefer F, Spanagel R (2009) Cue-induced alcohol-seeking behaviour is reduced by disrupting the reconsolidation of alcohol-related memories. Psychopharmacology (Berl) 205:389-397.

Voorn P, Gerfen CR, Groenewegen HJ (1989) Compartmental organization of the ventral striatum of the rat: immunohistochemical distribution of enkephalin, substance $\mathrm{P}$, dopamine, and calcium-binding protein. J Comp Neurol 289:189-201.

Wang X, Li W, Williams M, Terada N, Alessi DR, Proud CG (2001) Regulation of elongation factor 2 kinase by p90(RSK1) and p70 S6 kinase. EMBO J 20:4370-4379.

Wang XY, Zhao M, Ghitza UE, Li YQ, Lu L (2008) Stress impairs reconsolidation of drug memory via glucocorticoid receptors in the basolateral amygdala. J Neurosci 28:5602-5610.

Xu CM, Wang J, Wu P, Zhu WL, Li QQ, Xue YX, Zhai HF, Shi J, Lu L (2009) Glycogen synthase kinase 3beta in the nucleus accumbens core mediates cocaine-induced behavioral sensitization. J Neurochem 111:1357-1368.

Zahm DS, Brog JS (1992) On the significance of subterritories in the "accumbens" part of the rat ventral striatum. Neuroscience 50:751-767.

Zangen A, Solinas M, Ikemoto S, Goldberg SR, Wise RA (2006) Two brain sites for cannabinoid reward. J Neurosci 26:4901-4907. 